\section{Omission training of the jaw-movement response of the rabbit to a water US*}

\author{
I. GORMEZANO and GEORGE W. HILLER \\ University of Iowa, Iowa City, Iowa 52240
}

Twelve pairs of rabbits were run in a yoking procedure in which an anticipatory jaw-movement $C R$ by the contingent $S$ resulted in omission of the water US to the pair of Ss. Although Ss in the contingent omission and yoked groups revealed similar asymptotic levels of responding, the contingent omission Ss showed a more rapid rate of acquisition of CRs and longer CR latencies. The relevance of these findings to a law of effect account of classical conditioning was discussed.
Sheffield (1965) introduced the omission training procedure as a technique for testing the persistent theoretical contention that CRs are reinforced through a Thorndikian law of effect. In its most general form, the law of effect account holds that CR-US overlap modifies the sensory consequences of the US (i.e. attenuates a noxious US or enhances the appetitive properties of a positive US) to provide the source of reinforcement of CRs (e.g., Hebb, 1956 ; Perkins, 1955, 1968 ; Schlosberg, 1937). Because the presumed reinforcement mechanism of CR-US overlap can become operative only after an anticipatory CR has been made, Perkins $(1955,1968)$ has invoked adventitious responding, a factor extrinsic to the theory, to account for initial $\mathrm{CR}$ occurrence. On the other hand, Schlosberg (1937) and Maier \& Schneirla (1942) appealed to CS-US contiguity for initial CR occurrence, while holding that the subsequent course of development of CRs may be determined by the law of effect.

The omission paradigm is one in which an appetitive US is withheld if an anticipatory CR occurs and the US is presented whenever the anticipatory CR does not occur. Thus, the omission standpoint of Thorndikian principles, the organism is "rewarded" with the appetitive US whenever he fails to make a CR. Furthermore, since under the omission procedure the presumed reinforcing event of CR-US overlap does not occur, Perlins's formulation would lead to the expectation of no conditioning. Yet, successful acquisition of CRs under the omission procedure has been reported for the dog's salivary response with a food

*This research was supported by Grant GB-7907X from the National Science Foundation. Requests for reprints should be addressed to I. Gormezano, Dept. of Psychology, University of Iowa, Iowa City. Iowa 52240. procedure is one in which, from the pellet US (Sheffield, 1965) and for the rat's licking response to a water US (Patten \& Rudy, 1967). However, the Schlosberg/Maier and Schneirla version of the law of effect would lead to the prediction that, relative to the performance of an appropriate (noncontingent) classical conditioning control group, the omission paradigm will lead to a lower level of performance. The present investigation was concerned with making such a comparison.

\section{METHOD}

The apparatus and jaw-movement recording technique have been described in detail elsewhere (Gormezano, 1972; Smith, DiLollo, \& Gormezano, 1966). The CS was a 72-dB (re .0002 dynes $/ \mathrm{cm}^{2}$ ) $1,000-\mathrm{Hz}$ tone of $500 \mathrm{msec}$ duration and was terminated with US onset. The US was a 1-cc squirt of distilled water of 300 msec duration and was delivered into the rabbit's oral cavity via a permanently implanted polyethelene cannula in the left cheek. The signal from the jaw-movement transducer was amplified and recorded on an Offner (Type $R$ ) oscillograph. For all Ss, a CR was defined as a pen deflection of $1 \mathrm{~mm}$ (a jaw movement of $.25 \mathrm{~mm}$ ) or more occurring in the 50-500-msec interval from CS onset.

Twelve naive albino rabbits, 80-100 days old, were assigned randomly to each of two groups: a contingent omission group (Group O) and a yoked classical conditioning control group (Group Y). Two Ss, one from each group, were run simultaneously in a yoking procedure whereby the occurrence of a jaw-movement CR by the $S$ in Group $O$ triggered a comparator circuit which resulted in the omission of the US for both Ss on that trial. If the $S$ in Group $O$ failed to make a CR, the US was presented to both Ss $500 \mathrm{msec}$ after CS onset. Six days before the start of training, each $S$ was anesthetized, a fistula was perforated through the left cheek, and a polyethylene cannula secured in the fistula. On the second postoperative day, the S's daily water access was limited to exactly $90 \mathrm{cc}$ per day throughout the experiment. Prior to the availability of water on the fifth postoperative day, all Ss were adapted to the apparatus and their base rate of jaw movements obtained at times corresponding to the $\mathrm{CR}$ scoring interval of subsequent acquisition sessions. Twenty-five days of acquisition training were begun on the sixth postoperative day. All Ss

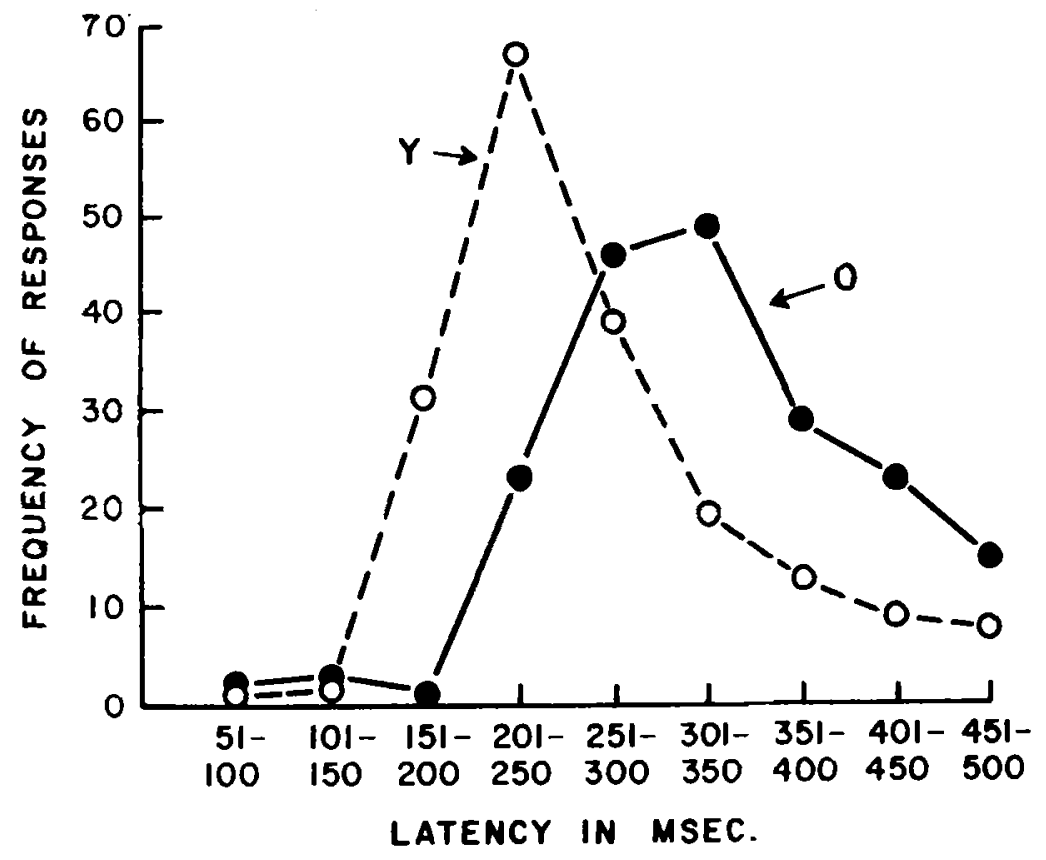

Fig. 1. The distribution of CR latencies in milliseconds for all of acquisition. 


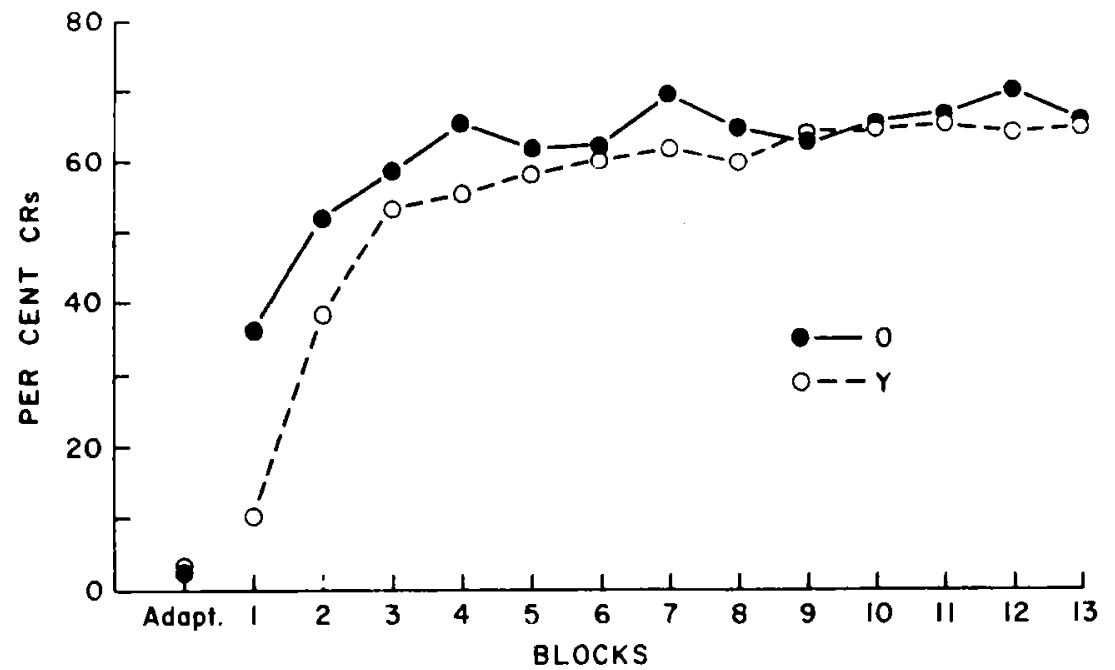

Fig. 2. The percentage of CRs plotted for adaptation and acquisition.

received 24 trials per day at random intertrial intervals of 200,240 , and $280 \mathrm{sec}$ (mean $240 \mathrm{sec}$ ). The amount of water delivered to each $\mathrm{S}$ during each acquisition session was calculated, and a supplement was given to each $\mathrm{S}$ approximately $1 / 2 \mathrm{~h}$ after each session to bring each S's total daily water intake up to $90 \mathrm{cc}$.

\section{RESULTS}

Figure 1 presents the distribution of response latencies of Groups $\mathrm{O}$ and $\mathrm{Y}$ for all of acquisition training. Inspection of the figure indicates that the distributions were clearly unimodal, with Group $\mathrm{O}$ showing a flatter distribution and a longer modal CR latency than Group Y. Figure 2 presents the results of plotting the mean percentage CRs in adaptation and acquisition. The initial data points are the percentages of responses occurring during adaptation. The first block is a plot of the mean percentage CRs for the first day of acquisition, and the remaining data points are based upon the mean percentage CRs on each 2-day block of acquisition. Examination of the figure indicates that the base rates of responding during adaptation were essentially alike for both groups. Subsequently, Group $O$ proceeded to demonstrate a faster rate of acquisition than did Group $Y$ and continued to maintain its superior performance until attaining asymptote. At asymptote, both groups stabilized their levels of responding at around $65 \%$. It is of interest to note that $C R$ acquisition was acquired under a decreasing frequency of US occurrence and that asymptotic responding was maintained under a partial reinforcement schedule of about $35 \%$. An analysis of variance on the percentage CRs revealed a significant effect of days $(F=9.38, \mathrm{df}$ $=24 / 528, \mathrm{p}<.01$ ) and Groups by
Days $(F=2.15$, df $=24 / 528, p<.01)$, but groups did not approach significance $(F<1.00)$.

\section{DISCUSSION}

The present observation of acquisition of jaw-movement CRs under the omission paradigm is consistent with the previous findings of Sheffield (1965) and Patten \& Rudy (1967) and is counter to Perkins's law of effect account of classical conditioning. Conceivably, advocates of Perkins's formulation could argue that nonanticipatory CRs may have overlapped the US in the interval from US onset to provide the source of reinforcement for anticipatory CRs. However, such an assertion could not be tested, since the occurrence of such nonanticipatory CRs could not be distinguished from URs.

The failure to obtain a significant groups effect in the omission-yoked contrast is related to the Schlosberg/Maier and Schneirla version of the law of effect account of classical conditioning. Specifically, their formulation would lead to the expectation that, in comparing omission and classical conditioning procedures in which the pattern and number of US occurrences were the same, performance under the omission procedure should be inferior. Such an expectation would be predicated on their assumption that Ss under the classical procedure are subject to two (additive) sources of reinforcement: reinforcement through CS-US contiguity on those trials in which the $\mathrm{CR}$ fails to occur, and reinforcement through CR-US overlap on those trials in which the CR does occur. On the other hand, under the omission procedure, there would be the counterposing of the reinforcing effect of CS-US contiguity when the CR fails to occur, with the presumed punishing effect of omission of the appetitive US when the CR does occur. Rejection of the Schlosberg/Maier and Schneirla formulation on the basis of the present finding of no significant groups effect would require proof of the null hypothesis. Although this cannot be done, it is proper to indicate that with 14,400 observations, the power of the experiment was considerable. Furthermore, the finding of a significant Groups by Days interaction, reflecting a superior rate of acquisition of CRs under the omission procedure, provides additional disconfirmation of the applicability of the Schlosberg/Maier and Schneirla formulation to the present conditioning preparation.

The observation of a superior rate of acquisition of CRs under the omission procedure, while embarrassing to the Schlosberg/Maier and Schneirla formulation, is not without difficulties of interpretation. The problem of interpretation is occasioned by the fact that not only is the US omitted whenever the omission $S$ makes a $C R$, but also by the fact that the US is presented whenever the omission $\mathbf{S}$ fails to make a CR. Since both aspects define the contingency differential holding between omission and yoked Ss, either or both factors may have been responsible for the superior rate of acquisition of CRs in the omission group. Indeed, Moore \& Gormezano (1961) and Gormezano (1965), in reporting similar observations of superior acquisition performance of avoidance Ss over yoked classical condition control Ss for human eyelid and rabbit eyelid conditioning, respectively, offered an interpretation that emphasized the contribution of the contingency of US presentation upon absence of the CR. Specifically, it was hypothesized that the superior performance of avoidance Ss was due to their receiving the US when "needed," i.e., whenever a CR failed to occur, whereas, for yoked Ss, no such consistent relationship existed.

Basically, the Moore-Gormezano hypothesis is a uniprocess reinforcement interpretation that assumes that the associative contribution of a US is greater when a $\mathrm{CR}$ fails to occur than when a CR does occur. [Most recently, Prokasy (1972, p. 138), employing a two-phase conditioning model to human eyelid conditioning data obtained under the conventional classical conditioning paradigm, has provided additional support for the Moore-Gormezano hypothesis.] Given that the avoidance procedure is simply a subset of the more general omission training paradigm in which the US is noxious, 
the Moore-Gormezano hypothesis can provide a similar interpretation of the presently observed superior rate of acquisition of CRs of the omission Ss. 1 Furthermore, the longer modal CR latencies for omission Ss, and the observation by Moore \& Gormezano (1961) and Runquist, Sidowski, \& Gormezano (1962) of longer modal CR latencies for avoidance Ss than for classically conditioned yoked control Ss, are findings consistent with the uniprocess "need" interpretation that omission and avoidance Ss were going through cycles of acquisition (on CS-US trials) and extinction (on CR-US omission trials).

\section{REFERENCES}

CHURCH, R. M. Systematic effect of random error in the yoked control design. Psychological Bulletin, 1964, 62, 122-131.

GORMEZANO, I. Yoked comparisons of classical and instrumental conditioning of the eyelid response; and an addendum on "voluntary responders." In W. F. Prokasy
(Ed.), Clcssical conditioning: $A$ s y m p os i um. N e w York: A ppleton-Century-Crofts, 1965.

GORMEZANO, I. Investigations of defense and reward conditioning in the rabbit. In A. H. Black and W. F. Prokasy (Eds.), Classical conditioning II: Current research and theory. New York: Appleton-Century-Crofts, 1972.

HEBB, D. O. The distinction between "classical" and "instrumental." Canadian Journal of Psychology, 1956, 10, 165-166.

MAIER, N. R. F., \& SCHNEIRLA, T. C. Mechanisms in conditioning. Psychological Review, 1942, 49, 117-134.

MOORE, J. W., \& GORMEZANO, I. Yoked comparisons of instrumental and classical eyelid conditioning. Journal of Experimental Psychology, 1961, 62, 552-559.

PATTEN $R$, L RUDY J $W$. The Sheffield omission of training procedure applied to the conditioning of the licking respcisse int rats. Psichonomic Science, $1967,8,463-464$

PERKINS, C. C.. JR. The stimulus conditions which follow learned responses. Psychological Review, 1955, 62, 341-348.

PERKINS, C. C., JR. An analysis of the concept of reinforcement. Psychological Review, 1968, 75, 155-172.
PROKASY, N. F. Developments with the two-phase model applied to human eyelid conditioning. In A. H. Black and W. F. Prokasy (Ed.), Classical conditioning $I I$ : Current research and theory. New York: Appleton-Century-Crofts, 1972.

RUNQUIST, W. N., SIDOWSKI, J., \& GORMEZANO, I. Yoked comparisons of classical and avoidance conditioning in differential conditioning of the eyelid response. Psychological Reports, 1962, $11,43-50$.

SCHLOSBERG, $H$. The relationship between success and the laws of conditioning. Psychological Review, $1937,44,379-394$.

SHEFFIELD, F. D. Relation between classical conditioning and instrumental learning. In W. F. Prokasy (Ed.), Clossical conditioning: A symposium. New York: A ppleton-Century-Crofts, 1965.

SMITH, M. C., DiLOLLO, V., \& GORMEZANO, I. Conditioned jaw movement in the rabbit. Journal of Comparative \& physiological Psychology, $1966,62,479-483$

$$
\text { NOTE }
$$

1. Church (1964) has provided a general critique of yoked control designs. It will be demonstrated elsewhere that Church's argument is not applicable to the "need" interpretation of omission-yoked and avoidance-yoked contrasts. 